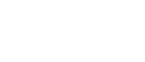

\title{
Autism in Higher Education: dissonance between educators' perceived knowledge and reported teaching behaviour
}

\section{Rhoda von Below, Elliott Spaeth \& Chiara Horlin}

To cite this article: Rhoda von Below, Elliott Spaeth \& Chiara Horlin (2021): Autism in Higher Education: dissonance between educators' perceived knowledge and reported teaching behaviour, International Journal of Inclusive Education, DOI: 10.1080/13603116.2021.1988159

To link to this article: https://doi.org/10.1080/13603116.2021.1988159

\section{(C) 2021 The Author(s). Published by Informa UK Limited, trading as Taylor \& Francis Group}

\section{央 Published online: 22 Oct 2021.}

Submit your article to this journal $₫$

Џll Article views: 87

Q View related articles $\square$

View Crossmark data $\nearrow$ 


\title{
Autism in Higher Education: dissonance between educators' perceived knowledge and reported teaching behaviour
}

\author{
Rhoda von Below ${ }^{\mathrm{a}}$, Elliott Spaeth (1D) ${ }^{\mathrm{b}}$ and Chiara Horlin (1D ${ }^{\mathrm{a}}$ \\ ${ }^{a}$ School of Psychology, University of Glasgow, Glasgow, UK; ${ }^{\text {}}$ Academic and Digital Development, \\ University of Glasgow, Glasgow, UK
}

\begin{abstract}
This study explores the autism knowledge and awareness of educators in Higher Education (HE) as well as their attitudes towards accommodating autistic students within their teaching. Semi-structured interviews were used to allow for in-depth investigation of this topic. Thematic analysis uncovered a striking dissonance between educators' positive attitudes towards accommodating autistic students and their actions in the classroom. A range of additional themes and subthemes interacted with the concept of dissonance. Even though participants self-described as having expert knowledge of autism, an attitude-behaviour gap was evident. Impact on inclusivity for autistic students is discussed, alongside recommended directions for future study and practice.
\end{abstract}

\section{ARTICLE HISTORY}

Received 28 January 2021 Accepted 27 September 2021

\section{KEYWORDS}

Autism; Higher Education; teachers; inclusive education

\section{Introduction}

Autism Spectrum Disorder, as described in the Diagnostic and Statistical Manual of Mental Disorders, is a neurodevelopmental diagnosis characterised by social communication deficits, sensory sensitivities, as well as restricted, repetitive or stereotyped patterns of activities and interests (American Psychiatric Association 2013). Autism prevalence varies from $1 \%$ to $2.6 \%$ of the general population, (Elsabbagh et al. 2012; Randall et al. 2016; Sun et al. 2019), with the latest NHS survey stating that approximately $1-2 \%$ of the UK's population have an autism diagnosis (Brugha et al. 2014; NHS Digital 2020). However, due to significant NHS waiting times large numbers of adults and families seeking diagnosis privately so these rates may still be an underestimate. When speaking or writing about autistic individuals it is important to utilise the language preferred within the autism community. Throughout this research article the term 'autistic student' will be adopted to reflect autistic self-advocates' and the neurodiversity movement's preference for identity first language (Kapp et al. 2013; Kenny et al. 2016). Autism Spectrum Condition (ASC) will be used as the neurodiversity movement, as well as some 
researchers, reject language that suggests deficit, impairment, or disorder (BaronCohen 2000; Rosqvist, Stenning, and Chown 2020). Non-autistic students will be referred to as 'neurotypical students' (Harris 2017), although it is acknowledged that students may be neurodivergent without being autistic.

\section{Autism in Higher Education (HE)}

While current research has not precisely identified the rates of autism within Higher Education ( $\mathrm{HE})$, there has been a sharp increase in the prevalence of neurodivergent conditions in UK schools between 2010 and 2019 (McConkey 2020), and thus an increasing number of neurodivergent students are progressing to $\mathrm{HE}$ (Pino and Mortari 2014). A 2021 Parliamentary report states that $14.3 \%$ of full-time HE home students and 19\% of part-time students declared at least one disability in the 2019/2020 academic year in England (Office for Students 2021) providing an overall estimate of 17.3\%. In Scotland the estimates are only based on data from first degree entrants, however these estimates are similar to England at around 13\% (HESA 2019). It is important to note however, that these percentages are likely a lower bound estimate given that, for a variety of reasons many students choose not to share their diagnosis with their University (Getzel 2008). In Scotland statistics related to autism diagnosis in $\mathrm{HE}$ students specifically is typically clustered with mental health diagnoses. However, due to the trebling in reporting of this specific diagnosis, further exploration has identified that 3\% of first-degree entrants disclose an autism diagnosis (Commissioner for Fair Access 2019). In England, reporting rates are similar at around 4\% (Hubble and Bolton 2021). Again, these rates are likely to be an under-estimation of the true numbers of autistic students.

Considering that about $46 \%$ of the autistic population shows average to above average intellectual abilities (CDC 2014), this suggests a significant proportion of people enrolling at university are likely to be autistic (Pugliese and White 2014). Autistic people may have skills particularly suited to HE, such as proficient memory skills, a focus on detail, and creative thoughts, as well as passionate interests. and a strong desire to acquire accurate knowledge (Drake 2014; Gobbo and Shmulsky 2014; Van Hees, Moyson, and Roeyers 2015). Because autism presents heterogeneously there are also vast differences in coping mechanisms and skills in autistic students (Gobbo and Shmulsky 2014).

However, even when exhibiting some of these skills, autistic students have been reported to have a heightened risk for academic and personal challenges, and thus might not reach their full potential at university (Pinder-Amaker 2014; VanBergeijk, Klin, and Volkmar 2008). Research suggests that autistic students are likely to be disadvantaged at university, with only $27 \%$ reporting that their social needs were met and $40 \%$ reporting that their academic needs were met (Cai and Richdale 2016). More than $50 \%$ of autistic students considered themselves to not be academically successful, and were unhappy with their workload (Jackson et al. 2018). Autistic students were found to have only a $40 \%$ likelihood of successfully completing their studies, about $12 \%$ less likely than the general student population (Newman et al. 2011). The reasons for these poorer outcomes, and the barriers and challenges that might cause them, are manifold, complex and often intersecting. 


\section{Staff-centred challenges}

Often, the first hurdle for autistic students in receiving support within universities involves informing the university of their condition. Autistic people often experience significant barriers to formal diagnosis in childhood, adolescence, or young adulthood, particularly for girls and women (Bargiela, Steward, and Mandy 2016; Rutherford et al. 2016) or those without additional intellectual impairments (Mayes et al. 2014). Indeed, due to misdiagnosis, co-occurrent diagnoses, and stereotyped perception of autism there is increasing recognition of a 'lost generation' (Lai and Baron-Cohen 2015; Stagg and Belcher 2019) of undiagnosed adults with autism that may represent up to $50-60 \%$ of the true autistic population (Baron-Cohen et al. 2009). Some of these people may never receive a diagnosis, or only receive it as adults. Even for those able to receive a diagnosis before arriving at university, many students are hesitant to share their autism diagnosis to the relevant service, fearing discrimination, bullying, stigmatisation, and a lack of understanding (Cai and Richdale 2016; Cox et al. 2017; Sarrett 2018; Vincent et al. 2017).

If a diagnosis is shared Disability Services within a HE institution can work with students to agree accommodations (adjustments to teaching methods or assessments aimed at supporting autistic students in HE). However, accommodations are often denied, and even when granted they can be overly generic and fail to address sensory, social, academic, or psychiatric needs (Jansen et al. 2018; Kuder and Accardo 2018; Sarrett 2018). In addition, many students experience lecturers refusing to implement granted accommodations, despite their legal responsibility to comply (Sarrett 2018) under the UK's Equality Act (2010). In this way, university staff have a huge amount of power to impact the experience of autistic students.

For lecturers, this power goes beyond the granting and implementation of accommodations, and into the way learning and teaching activities are designed, developed, and facilitated. This necessitates moving away from a medical model of disability, where impairment is thought to lie within the individual, to a social model, where impairment is conceptualised as often caused by unsuitable environments. Universal Design for Learning (UDL) is an approach that advocates for proactively making learning and teaching more inclusive for all students rather than only making allowances for students who have managed to obtain sufficient accommodations (Burgstahler 2010). This is particularly important for 'invisible' conditions, like autism, where they might not be apparent to an observer (Zeedyk, Bolourian, and Blacher 2019).

Focus groups have highlighted that autistic students often feel that peers or lecturers do not accept them or have insight into the difficulties they might face (Jansen et al. 2018). Similarly, Moriña Díez, López, and Molina (2015) found that disabled students perceived lecturing staff as creating 'more barriers than bridges' (155) in relation to inclusivity. A lack of training for these staff was identified as a persistent issue. Autism awareness and knowledge within HE teachers is essential for providing students with an autism friendly university environment, where they can use their strengths to thrive.

Complicating the issue further is the possibility that those with little knowledge about autism may be unaware of their own deficit in this area. McMahon, Stoll, and Linthicum (2020) showed that within the general population there was no relationship between scores on perceived autism knowledge and those on actual autism knowledge, and that those who were less knowledgeable overestimated their knowledge significantly. This misjudgement could lead to teachers making assumptions about autism without 
consulting further information, resulting in lack of implementation of inclusive teaching practices.

There is a need for research exploring how teachers in HE perceive autistic students and accommodate them into their curriculum. The aim of this study is to qualitatively investigate what attitudes teachers have towards autistic students, their opinions about students sharing their diagnosis, and their willingness to accommodate by conducting in-depth semi-structured interviews.

\section{Materials and methods}

\section{Ethics}

This study gained ethical approval from the College of Science and Engineering ethical review committee at the University of Glasgow. Written and informed consent was obtained from all participants, who received no compensation for participation.

\section{Participants}

Participants $(N=5)$ were recruited from a pool who had registered interest. Four out of five participants were female, and all taught in different colleges within the university, with an average teaching experience of 9.2 years. All considered themselves somewhat experts on autism, either due to a close family member receiving a diagnosis or a vocational focus on autism.

\section{Procedure}

Participants were interviewed individually for 30-45 minutes. The interview protocol included three main areas, which together address all aims of the research project. The first area probed for general knowledge and experience with autism, the second focused on personal experience with autism in $\mathrm{HE}$, and the third included questions about the curriculum, such as delivery of course content, accommodations, assessment and students informing about their diagnosis.

\section{Analysis}

Interviews were audiotaped and transcribed verbatim. Transcripts were analysed based on the six phases of thematic analysis (Braun and Clarke 2006). Thematic analysis was chosen for its inductive analytical approach which does not rely on any rigid theoretical framework, allowing the researcher to incorporate alternative perspectives. The primary rater first analysed the transcripts to identify shared perspectives, repeated patterns of meaning, and areas of disagreement. Subsequently, these statements and discussions were given preliminary codes to summarise their meaning. These codes were grouped into themes and re-analysed and refined. These themes were then compared to the outcome of the second-rater analysis and re-analysed until consensus was reached. 


\section{Results}

The overarching theme that emerged was 'dissonance', describing the cognitive dissonance that participants seemed to be experiencing between their knowledge of autism and their application of this knowledge within their learning and teaching practice. Six themes and 11 subthemes were found to interact with the concept of dissonance, grouped under three important factors connected to the dissonance, detailed in Figure 1. The first factor, Facets of Autism Awareness, comprises three subthemes describing different aspects of autism that teachers are aware of in HE. Secondly, Factors Contributing to the Dissonance, encompasses factors that increase dissonance, on both a structural and personal level. The third cluster, Ways to Reduce the Dissonance, revolves around the educators' actions, ideas and hopes on how to improve their teaching.

\section{Dissonance}

The interviews brought to light that while all participants considered themselves to have high or at least adequate knowledge of autism within $\mathrm{HE}$ this did not necessarily translate into their own behaviour as educators. This was expressed in a dissonance between their knowledge and their ability to apply this knowledge to their own interactions with autistic adults. Furthermore, they were unaware of this dissonance and its potential impact on the inclusivity of their practice.

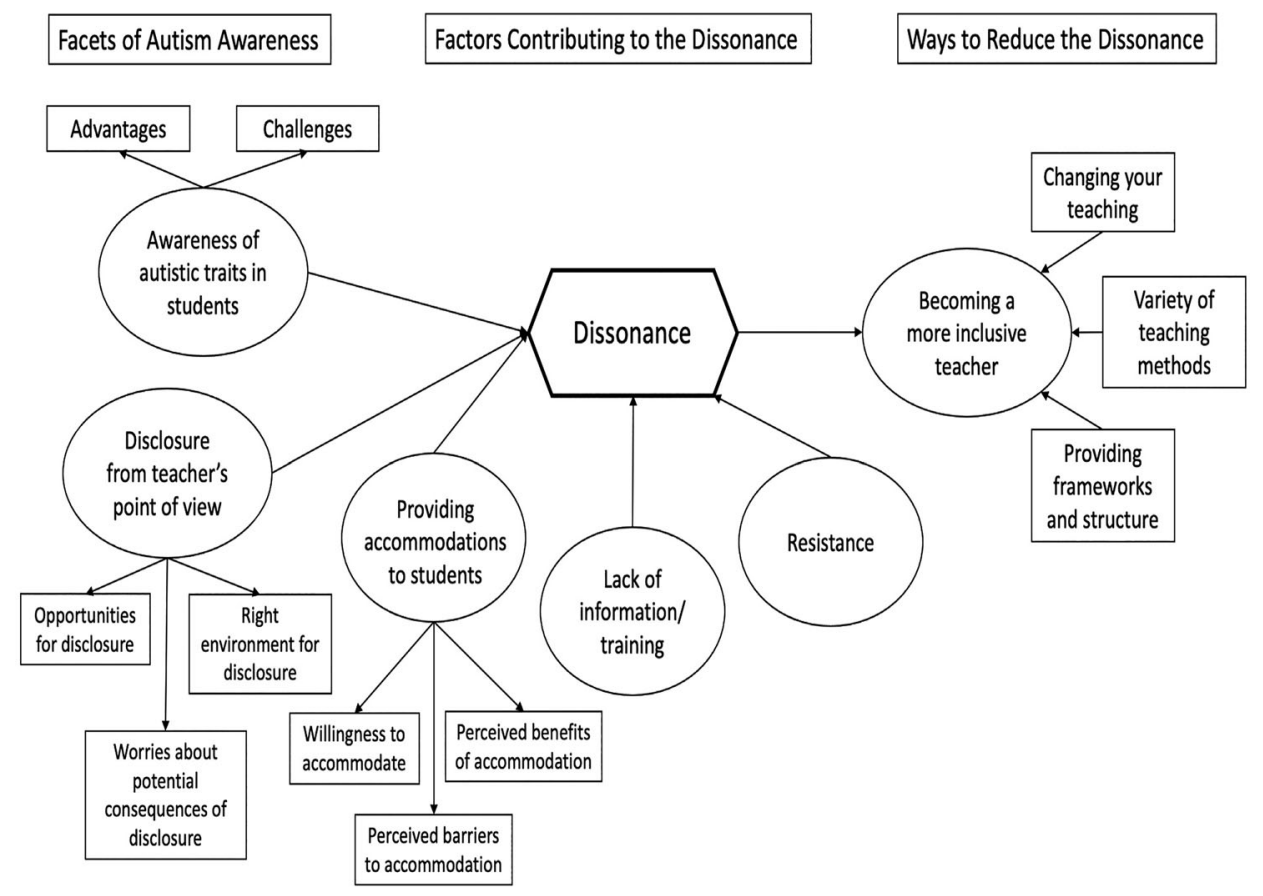

Figure 1. Thematic map of themes and subthemes. The supraordinate theme dissonance illustrates the interaction of the different themes under the three aspects of autism in HE. Themes are represented by circles, subthemes by squares/rectangles. 
Because we are all therapists, we consider inclusive communication and inclusive teaching to be good practice for absolutely everybody anyway, so it's never a challenge for us. (Karen, 187-189)

Even though Karen reflects on inclusivity as being so ingrained in her teaching that she does not struggle with it, she later reveals that she does experience these struggles. This does not happen consciously, and she is not able to recognise the dissonance within her statements.

You know it really is going over and above. And we do it, but it is really challenging trying to do that kind of teaching. (Karen, 231-232)

Their [autistic students'] contributions are welcome, but they do present a challenge for teaching in managing to keep to topic. (Karen, 131-133)

Most teachers were aware that they will have taught autistic students without knowing so, especially those that teach large classes. However, the dissonance between this knowledge and their teaching practices is stark. Elsbeth clearly states that she knows she will most likely have autistic students in her classroom without being aware of it, but later suggests she would adapt her teaching to make it more inclusive only once she knows she is teaching an autistic student.

I will be teaching students that I either don't know have autism, or have not disclosed. (Elsbeth, 62-63)

I think probably I have like a generic student in mind [when designing assessments]. (Elsbeth, 249-250)

I'm trying to think of other things that I take into account when I'm teaching. That might vary if I knew that I had an autistic adult in my classroom. (Elsbeth, 71-72)

\section{Facets of autism awareness}

\section{Awareness of autistic traits in students}

Being autistic in HE was linked with both opportunities and challenges. The teachers reported that the way that autistic students saw and processed the material in their courses sometimes led to an advantage over their peers, especially when it concerned structurally difficult topics or required attention to detail, providing opportunities for the students. However, some also presented outdated notions about autism, such as the belief about strong systematising abilities in all autistic individuals, which adds to the overarching theme of dissonance.

I suppose it would just be (...) that kind of systematising ability, being able to bring an additional perspective to a situation. (Karen, 125-127)

The teachers also experienced that autistic traits could lead to challenges for the students. They found that students struggled with communication within class, both in tasks such as group work, as well as in academic writing. Educators highlighted that specifically tasks and assessment that involved social interactions could present challenges.

Presentations, I'd say that's the one that comes up most often, that people just don't feel comfortable presenting and answering questions from their peers. (Elsbeth, 209-210) 


\section{Sharing diagnoses from a teacher's point of view}

Students sharing their diagnosis was recognised as the most important step towards receiving accommodations, but there were different elements of it that the educators recognised. It was emphasised that the right environment needed to be established for students to feel confident enough to share. Furthermore, the educators strongly believed in the individual person's right to choose the appropriate moment when to inform, but also emphasised that universities need to improve in providing environments that allow students to feel comfortable sharing this information.

I just actually feel, it's a great shame if they feel they can't disclose. And in an ideal world, they wouldn't need to. But we are not there yet, so it really does help if they do. (Karen, 350-352)

The opportunities to share diagnosis were emphasised by all educators, who believed that by sharing their diagnosis students were supported in a way that made them better and happier students, and also supported them as teachers in knowing how to best provide that support and ultimately achieve a nurturing environment.

I could see such a big difference in the way I was interacting with that person and how he was behaving and how he was learning that it made me realise that it is much easier as a teacher if you know what is going on (...). So, I will encourage them to disclose it, because then you can adapt things. (Mark, 271-276)

While all respondents expressed support for the informing of an autism diagnosis, they also expressed worries about the potential consequences of informing. While they viewed themselves as aware and open, they were wary that some of their colleagues might not be informed enough to handle the experience appropriately. Educators could understand how negative attitudes towards autism could prevent students from wanting to inform teachers of their diagnosis.

Quite often people have a kind of unconscious stereotype of autism and that being a very specific type of interest, and a young male white person, so if you don't know that actually you can be a fifty year old female (...), you might get some lecturers who'll go, we'll they are not autistic, that's rubbish. Because they don't necessarily understand the differences there. (Elsbeth, 327-332)

\section{Providing accommodations to students}

Accommodations were seen as a levelling platform for autistic students and as great opportunities to support the students in the way they needed it, evidenced the educators' willingness to accommodate.

For me it would be fair to change the way of assessing. Because I think, at the end of the day, what you want to assess is that the knowledge is there, and it doesn't matter. It is just a shame that you do it in a way that the person can't show it. (Mark, 246-249)

Perceived benefits of accommodation were mentioned by all the educators, who felt that making changes to support their autistic students could make the learning environment better for all students.

I tend to feel that accommodations tend to (...) improve teaching for everyone. (Jennifer, 296-297) 
Educators were also aware of the perceived barriers to accommodation, based on restrictions through course requirements, as well as structural problems through the university, but also the nature of the course that the students enrolled in.

We mostly try to come up with an alternative um. But there are restrictions to that in terms of course credit, so for instance, all students have to sit the exam. (Elsbeth, 115-117)

\section{Factors contributing to the dissonance}

\section{Lack of information and training}

The provision of information and training depended strongly on the institution itself, but the majority of participants indicated the wish for more support in educating themselves through training and seminars and the availability of information both from the university and the disability services. Teachers expressed surprise and disdain at finding out that the training they receive does not cover autism in more depth.

I realised there is a lot of autism in higher education um but, that this had never been addressed explicitly in any of my pedagogical training, it had never been talked about anywhere that I had been aware off. (Jennifer, 43-46)

Participants found it was not an easy task to find the information provided by their university. They noted that if this was difficult for those actively seeking this information, then it would be highly unlikely that anyone would come across it by chance.

Because if there is like one day a year and you can't make it (...) then you've missed your turn. (...) I've tried extremely hard to inform myself and I've not been able to, despite really looking and so if you're not really looking then you, yea. (Hannah, 219-223)

Resistance. While the teachers that were interviewed were open to inclusive teaching, all were able to present other views in academia. Some spoke about colleagues who did not change their teaching in ways that would support students rather than hinder them, while others commented on how academia can be ableist in its entirety. Overall, they showed disdain for those who openly resisted inclusive teaching or educating themselves on how to make their teaching more autism friendly.

I've had situations in the past where students have come to me and said I just don't feel comfortable speaking in front of other students, and the traditional approach to that and so many of my colleagues do it (...), will go 'Well you have to do it, you signed up for a language course, what do you think was going to happen?' (...) that doesn't make any sense to me, if I got a student I know is very capable and having that exam format is going to be detrimental to their performance, I just think what a terrible thing to do as an educator. (Hannah, 241-248)

\section{Ways to reduce the dissonance}

\section{Becoming a more inclusive teacher}

The teachers emphasised different methods they use to make their teaching more inclusive, especially changing your teaching to include everyone. This can include big changes such as rewriting lectures and changing assessments to implementing small changes like 
creating a welcoming environment through openly introducing the classroom as a space where differences are welcome and encouraged.

So there are ways in which you can, without accommodating, you could kind of say this is all normal and expected and you might do this and that's ok, in the same way I have started giving my pronouns when introducing myself, it's just a way of saying this is in the realm of the normal and expected. (Jennifer, 233-239)

In order to design teaching for a neurodiverse audience, teachers focused on incorporating a variety of teaching methods to ensure no one's academic strength is overlooked due to methods that do not foster said talent.

But I'm hoping by having variety and giving people kind of control over what they do might reduce stress. I don't know, but at least it will get, people will be able to showcase different kinds of talents and skillsets. (Jennifer, 404-405)

Emphasised by all educators was the need for providing framework and structure in their courses to enable students to follow the course however suits them best. Many of the teachers spoke about providing the space for students to prepare for lectures and seminars in order to be able to get the most out of them.

I've come to realise, it's a lot about passing on those frameworks I have in my head to help people make sense of a lot of information rather than teaching them information. (Jennifer, 164-166)

Taken together, the themes and subthemes draw a picture of relatively high autism awareness and knowledge. This, however, also plays into the overarching theme of dissonance between these high levels of knowledge and positive attitudes, and their teaching behaviour.

\section{Discussion}

As Pellicano, Dinsmore, and Charman (2014) emphasised, it is crucial to involve and consider perspectives from within the autism community in autism research. The first rater identifies as a typically developing student under the age of 25 , and therefore takes an outsider position in the analysis process. The second rater is an expert in the research area of both autism and education, as well as being a member of the autism community as a parent, therefore providing a different position and view to the first rater. Other authors of the paper are members of the autistic and wider neurodivergent community, leading to a well-balanced analysis and interpretation.

This study investigated autism awareness and knowledge of HE teachers within the UK, as well as their attitudes towards, and willingness to accommodate, autistic students. Participants deemed themselves to be knowledgeable and inclusive in their teaching. They talked about ways to make their teaching inclusive and how sharing their diagnosis and accommodations can help both the students and them as a teacher, as well as discussing potential downsides. However, it does not necessarily follow that these teachers, in practice, promote an inclusive atmosphere which makes autistic students feel accepted. The current study showed even though knowledge and awareness levels in teachers seemed to be high, a dissonance existed between the teacher's positive attitudes when 
it came to inclusive teaching and accommodating autistic students, and their actual teaching behaviour.

\section{The attitude-behaviour gap}

In environmental studies a widely used concept is the attitude-behaviour gap, which describes how people's attitudes are often only loosely translated into actions and behaviours (Farjam, Nikolaychuk, and Bravo 2019; Vigors 2018; Higham, Reis, and Cohen 2015). The concept of an attitude-behaviour gap can be readily applied to autism knowledge and awareness of HE teachers in the UK. While the teachers demonstrated mostly positive attitudes towards autistic students, accommodations, and inclusive teaching, a gap between their attitudes and their actual behaviour was found. The potential reasons behind this gap are manifold. Griffioen, Doppenberg, and Oostdam (2018) found that departmental attitude influenced how lecturers implemented change. While some departments changing and updating lectures was the norm, in others traditional teaching approaches were more valued, as new developments were thought to lower the standard of teaching. As such, lecturers who are knowledgeable about and have positive attitudes towards autism could struggle to adapt their teaching because of departmental culture and values. Cost is another factor, with Farjam, Nikolaychuk, and Bravo (2019) finding that behaviours are more likely to be implemented when connected with low costs. Within academia, where lecturers have to balance teaching, research and administrational tasks (Hay 2017) time is a scarce resource, and one which is key to restructuring one's teaching to be more inclusive.

\section{The implied student}

Another factor contributing towards the attitude-behaviour gap is the concept of the 'implied student', as coined by Ulriksen (2009), which refers to lecturers basing their teaching methods and programme structure on the student they expect to meet. Due to the marginalised status of neurodiversity, the 'implied student' is often assumed to be neurotypical, meaning that learning and teaching experiences may not be inclusive towards neurodivergent students. Starr-Glass (2020) further investigated the construct of the implied student, describing it as a convenient and compliant representation that allows lecturers to prepare their course. They argued that the distinction between the implied student and the real student needs to be recognised in order to make teaching fully inclusive and suggested practical steps to reconcile both. First, teachers must recognise the power and prevalence of the implied student, which informs thinking and decision making, but does not represent all students. Implied students tend to be representations of teacher's expectations, aspirations and values, summarising what they expect and to some extent prefer. Teachers should engage with real students to challenge the current implied student they are working with. Hearing stories or meeting autistic students could help lecturers to adjust their implied student. One participant in the current study emphasised that hearing personalised information and relating that to the students they are teaching made them realise how important it was for them to be inclusive. This supports Starr-Glass (2020)'s theory and emphasises the importance of 
making teachers aware of the challenges that autistic and otherwise neurodivergent students can face in their lectures.

\section{Implementing inclusive teaching}

Considering the findings from the current study in relation to literature on the attitudebehaviour gap and the implied student allows us to identify potential changes to practice to create a more inclusive environment for autistic (and otherwise neurodivergent) students. Supporting teachers in HE to close the gap between attitude and behaviour is of paramount importance. Some perpetuating factors of this gap, such as departmental culture and lack of time, are systemic, and therefore harder to resolve. Thus, this section will focus on issues that can be addressed by working directly with teaching staff.

Increasing awareness and knowledge about autism is an important first step. Although participants in this study demonstrated knowledge about autism, this is often not the case for teachers in HE. Participants in this study may have had higher existing levels of autism knowledge and openness to inclusive teaching than the general population because they came from a pool who had already registered interest in this topic.

Autism awareness training targets those who do not have enough knowledge of autism yet, or who need a refresher, and can result in increased knowledge about autism (Giannopoulou et al. 2019) and decreased stigma (Gillespie-Lynch et al. 2015). Crucially, McMahon, Stoll, and Linthicum (2020) found that those with little knowledge overestimated their awareness of autism, which is most problematic in people with key support or teaching roles. This was reflected in the current study in that those that heen teaching about autism did not attend inclusive teaching and autism classes, claiming that they didn't need to, but still displayed non-inclusive teaching practices. Therefore, it might be necessary to make autism awareness training mandatory, which is often not the case (Chown et al. 2018; Silva-Fletcher and May 2018). Additionally, Chown and Beavan (2012) highlight the important of autistic students being directly involved in any awareness training for HE staff to ensure their grounded knowledge of autism in HE students is directly informed by the personal accounts and thus the individualised person-centred approach recommended by Breakey (2006).

Although participants in this study demonstrated both knowledge about and positive attitudes towards autism, these are not always linked. White et al. (2019) found no connection between college students' autism knowledge and attitudes towards autistic children. In their study, 'knowledge' involved being able to identify characteristics of autism spectrum conditions, and 'attitude' related to the participants' assumptions about the autistic child. As such, it is important that any autism training focuses not only on knowledge of components of autism but also on debunking stereotypes that are built on a deficit approach to autism, and an introduction to the social model of disability.

Critical examination of the concept of the 'implied student' is a useful method for reconceptualising students who may differ from lecturers' existing expectations. Interpreting learning through a lens of an implied student, and with a fixed idea of how learning can be demonstrated, can lead to students who differ being viewed as deficient or unable to engage. It is important for teachers to realise they have an 'implied student' and the consequences this can have, as well as personal contact to students in order to change this (Starr-Glass 2020). Development opportunities relating to the implied 
student could be co-facilitated with one or more students, to emphasise the impact of the implied student on actual students. Just as there is increasing recognition of participatory research and the necessity for the autistic community to be centred within the process of knowledge production (Milton 2014; Milton and Moon 2012), so too should autistic expertise be centred within the production of awareness training and inclusive curriculums. The recent suggestion by Shmulsky, Gobbo, and Vitt (2021) of extending the culturally relevant pedagogy (CRP) approach that incorporates co-collaboration with students of diverse racial and ethnic backgrounds to students from the neurodivergent community may be a unique and productive possibility.

Universal Design for Learning (UDL) is a useful approach for designing learning activities and environments in a way that moves beyond the implied student, and as such should be a focus of relevant staff development initiatives. The three pillars of UDL are multiple means of engagement, representation, and action and expression, and a variety of practical strategies to implement these pillars are recommended by the Center for Applied Special Technology (CAST 2020). Burgstahler and Russo-Gleicher (2015) outlined a range of actions in line with UDL that could make post-secondary education more inclusive for autistic students, including: Proactively communicating how students can discuss learning concerns, and being approachable; outlining expectations regularly and clearly, including the importance of treating other learners with respect and how to engage in learning activities; assigning roles for each student within a group and scaffolding group work activity; allowing alternative means of participation, e.g. using post-it notes rather than speaking; recording lectures or otherwise making them available outside of live sessions; giving regular breaks; and dividing large tasks into smaller chunks. Other recent studies and systematic reviews have highlighted the success of responsive, individualised teaching for autistic students (Austin and Peña 2017) and the effectiveness of UDL for students with additional support needs across a number of different outcomes (AlRawi and AlKahtani 2021; James et al. 2021). Ultimately, it is vital to help staff understand that there are many ways for students to develop and demonstrate learning outcomes, and that doing so in an unexpected way does not mean a reduction in the quality of student learning.

It is important to also acknowledge the inherent complexity in balancing universality and diversity, and the possibility that an inclusive and flexible approach to learning and curriculum design may create new and different challenges for both learners and educators if too expansive in its scope. Despite codes and conventions like the Equality Act (2010) and the Convention on the Rights of Persons with Disabilities (2007), and their requirements for reasonable adjustments, support and accessibility, it is safe to say we are yet to reach that point of tension and unfortunately lean far more towards 'not enough' than 'too much'. Nor should the burden of this universally inclusive teaching landscape fall simply on the educator (as is the focus of this study) but on all layers of the government systems and institutions involved. Although there is great potential for governmental support initiatives like DSA-funded user-informed peer-mentoring for autistic HE students (Sims et al. 2016), we are far from these services being sufficiently available or effectively integrated (Adams 2020) and particularly for those students unable to receive formal diagnosis (upon which access to this support is contingent). Additionally, with the increasing commercialisation of higher education and expanding 
cohort sizes in many institutions, there may be only further institutional barriers to integrating the tailored person-centred approach that more effectively supports diverse needs (Breakey 2006; Madriaga and Goodley 2010; Waisman and Simmons 2018; Lee and Kim 2021) and known cognitive heterogeneity within the neurodivergent community (Márquez-Caraveo et al. 2021). While these systemic and institutional challenges remain, it is clearly vital that educators, as the 'frontline' of inclusive teaching are sufficiently aware and empowered enough that the attitude-behaviour gap as described in this study is no longer evident.

A meta-analytical integration of over 40 years of research on diversity training concluded that there are three key factors for successful diversity and inclusion trainings (Bezrukova et al. 2016). Firstly, it is important that the training is integrated into wider efforts of inclusion and diversity within the institution. Secondly, the length of the training was a significant factor, with trainings that are split over longer periods of time showing higher effectiveness. Lastly, when providing both the tools to practice inclusivity and the theory behind it, participants showed a better learning curve overall. Therefore, in higher education, these seminars need to teach lecturers the theory behind the implied student and the attitude-behaviour gap, as well as practical tools to improve their teaching.

It is crucial to understand that fundamentally integrating inclusive teaching is not something that can be achieved through one seminar. Lecturers need to be constantly aware of how they can adapt their teaching, and personal interactions and the implied student that they are utilising. This can be compared to a muscle that needs to be regularly exercised. Reflective cycles (Harvey 2019) or implemented check boxes could support this process, as well as regular training and an array of further professional development options. Crow and Smith (2005) found that co-teaching and the following reflective conversations are powerful mechanisms to reflect on one's own practices. Therefore, co-teaching following a diversity training session might support self-reflection and encourage teachers to start routinely implementing inclusive teaching practices.

\section{Conclusion}

The current study explored the awareness and knowledge of autism in HE teachers in the UK, as well as their attitudes towards accommodating autistic students in their classroom. Even with a modest sample size and the necessarily self-selective nature of participant recruitment, semi-structured interviews showed a dissonance between HE teachers' awareness, knowledge and attitude, and their actual behaviour as teacher. This was conceptualised as an attitude-behaviour gap, which can lead to teachers not implementing the knowledge about autism and diversity into their teaching. The results of the study suggest that more autism awareness training should be implemented so that all teachers increase autism knowledge. Furthermore, the 'implied student' that teachers work with needs to be changed to one representing a more diverse range of students. This could potentially be achieved through practical diversity seminars addressing biases. Overall, the study showed that even those teachers that deem themselves highly knowledgeable show evidence of an attitude-behaviour gap, indicating that practices need to be changed on a university-wide level. 


\section{Acknowledgements}

The authors wish to extend their thanks to the participants who contributed their time and experience, Mandie Boyle for her assistance in the thematic analysis, and Dr Harrison, who allowed us to utilise the ASK-Q.

\section{Disclosure statement}

No potential conflict of interest was reported by the author(s).

\section{Data availability statement}

The data that support the findings of this study are openly available through PsyArXiv at https:// psyarxiv.com/.

\section{Notes on contributors}

Rhoda von Below is a first class graduate of the Master of Arts (Soc) programme at the University of Glasgow.

Dr Elliot Spaeth is a Lecturer within the Academic and Digital Development Service at the University of Glasgow.

Dr Chiara Horlin is Lecturer within the School of Psychology and Neuroscience at the University of Glasgow.

\section{ORCID}

Elliott Spaeth (D) http://orcid.org/0000-0001-5446-0908

Chiara Horlin (1) http://orcid.org/0000-0003-4233-2030

\section{References}

Adams, J. 2020. "DSA Support for Disabled Students in Higher Education in UK: The Contribution of Specialist Mentoring." Journal of Inclusive Practice in Further and Higher Education 12 (1): 26-45.

AlRawi, Jamelh Moshbab, and Mohammed Ali AlKahtani. 2021. "Universal Design for Learning for Educating Students with Intellectual Disabilities: A Systematic Review.” International Journal of Developmental Disabilities, 1-9.

American Psychiatric Association. 2013. Diagnostic and Statistical Manual of Mental Disorders $\left(D S M-5^{\circledR}\right)$. Washington, DC: American Psychiatric.

Austin, Kimberly S., and Edlyn Vallejo Peña. 2017. "Exceptional Faculty Members Who Responsively Teach Students with Autism Spectrum Disorders." Journal of Postsecondary Education and Disability 30 (1): 17-32.

Bargiela, Sarah, Robyn Steward, and William Mandy. 2016. "The Experiences of Late-Diagnosed Women with Autism Spectrum Conditions: An Investigation of the Female Autism Phenotype." Journal of Autism and Developmental Disorders 46 (10): 3281-3294.

Baron-Cohen, Simon. 2000. "Is Asperger Syndrome/High-Functioning Autism Necessarily a Disability?" Development and Psychopathology 12 (3): 489-500.

Baron-Cohen, Simon, Fiona J. Scott, Carrie Allison, Joanna Williams, Patrick Bolton, Fiona E. Matthews, and Carol Brayne. 2009. "Prevalence of Autism-Spectrum Conditions: UK SchoolBased Population Study.” The British Journal of Psychiatry 194 (6): 500-509. 
Bezrukova, Katerina, Chester S. Spell, Jamie L. Perry, and Karen A. Jehn. 2016. “A Meta-Analytical Integration of over 40 Years of Research on Diversity Training Evaluation.” Psychological Bulletin 142 (11): 1227.

Braun, Virginia, and Victoria Clarke. 2006. “Using Thematic Analysis in Psychology.” Qualitative Research in Psychology 3 (2): 77-101.

Breakey, Christine. 2006. The Autism Spectrum and Further Education: A Guide to Good Practice. London: Jessica Kingsley Publishers.

Brugha, T., S. A. Cooper, F. J. Gullon-Scott, E. Fuller, N. Ilic, A. Ashtarikiani, and Z. Morgan. 2014. "Adult Psychiatric Morbidity Survey." Government Statistical Service. Accessed February 6, 2020. https://files.digital.nhs.uk/pdf/1/o/adult_psychiatric_study_ch6_web.pdf.

Burgstahler, Sheryl E. 2010. "Universal Design for Learning in Higher Education.” In Universal Design in Higher Education: From Principles to Practice, edited by Sheryl E. Burgstahler and Rebecca C. Cory, 1-26. Cambridge: Harvard Education Press.

Burgstahler, Sheryl, and Rosalie J. Russo-Gleicher. 2015. “Applying Universal Design to Address the Needs of Postsecondary Students on the Autism Spectrum." Journal of Postsecondary Education and Disability 28 (2): 199-212.

Cai, Ru Ying, and Amanda L. Richdale. 2016. "Educational Experiences and Needs of Higher Education Students with Autism Spectrum Disorder." Journal of Autism and Developmental Disorders 46 (1): 31-41.

Center for Applied Special Technology. 2020. “Cast.org. 2021. CAST: About Universal Design for Learning." http://www.cast.org/impact/universal-design-for-learning-udl.

Center for Disease Control and Prevention. 2014. "Prevalence of Autism Spectrum Disorder Among Children Aged 8 Years-Autism and Developmental Disabilities Monitoring Network, 11 Sites, United States, 2010." Morbidity and Mortality Weekly Report: Surveillance Summaries 63 (2): 1-21.

Chown, Nick, Joanna Baker-Rogers, Liz Hughes, Kleio Nicola Cossburn, and Pam Byrne. 2018. "The 'High Achievers' Project: An Assessment of the Support for Students with Autism Attending UK Universities.” Journal of Further and Higher Education 42 (6): 837-854.

Chown, Nick, and Nick Beavan. 2012. "Intellectually Capable but Socially Excluded? A Review of the Literature and Research on Students with Autism in Further Education." Journal of Further and Higher Education 36 (4): 477-493.

Commissioner for Fair Access. 2019. “Disabled Students at University: Discussion Paper.” Scottish Government Advanced Learning and Science Directorate. Accessed July 22, 2021. https://www. gov.scot/publications/commissioner-fair-access-discussion-paper-disabled-studentsuniversity/pages/1/

Cox, Bradley E., Kerry Thompson, Amelia Anderson, Amanda Mintz, Taylor Locks, Lindee Morgan, Jeffrey Edelstein, and Abigail Wolz. 2017. "College Experiences for Students with Autism Spectrum Disorder: Personal Identity, Public Disclosure, and Institutional Support." Journal of College Student Development 58 (1): 71-87.

Crow, Jayne, and Lesley Smith. 2005. "Co-Teaching in Higher Education: Reflective Conversation on Shared Experience as Continued Professional Development for Lecturers and Health and Social Care Students.” Reflective Practice 6 (4): 491-506.

Drake, Sara. 2014. "College Experience of Academically Successful Students with Autism.” Journal of Autism 1 (5). doi:10.7243/2054-992X-1-5.

Elsabbagh, Mayada, Gauri Divan, Yun-Joo Koh, Young Shin Kim, Shuaib Kauchali, Carlos Marcín, Cecilia Montiel-Nava, et al. 2012. "Global Prevalence of Autism and Other Pervasive Developmental Disorders.” Autism Research 5 (3): 160-179.

Farjam, Mike, Olexandr Nikolaychuk, and Giangiacomo Bravo. 2019. "Experimental Evidence of an Environmental Attitude-Behavior Gap in High-Cost Situations." Ecological Economics 166: 106434.

Getzel, Elizabeth Evans. 2008. "Addressing the Persistence and Retention of Students with Disabilities in Higher Education: Incorporating Key Strategies and Supports on Campus." Exceptionality 16 (4): 207-219. doi:10.1080/09362830802412216. 
Giannopoulou, Ioanna, Evdokia Pasalari, Panagiota Korkoliakou, and Athanasios Douzenis. 2019. "Raising Autism Awareness Among Greek Teachers." International Journal of Disability, Development and Education 66 (1): 70-81.

Gillespie-Lynch, Kristen, Patricia J. Brooks, Fumio Someki, Rita Obeid, Christina Shane-Simpson, Steven K. Kapp, Nidal Daou, and David Shane Smith. 2015. "Changing College Students' Conceptions of Autism: An Online Training to Increase Knowledge and Decrease Stigma." Journal of Autism and Developmental Disorders 45 (8): 2553-2566.

Gobbo, Ken, and Solvegi Shmulsky. 2014. "Faculty Experience with College Students with Autism Spectrum Disorders: A Qualitative Study of Challenges and Solutions." Focus on Autism and Other Developmental Disabilities 29 (1): 13-22.

Griffioen, D. M. E., J. J. Doppenberg, and R. J. Oostdam. 2018. “Organisational Influence on Lecturers' Perceptions and Behaviour Towards Change in Education." Studies in Higher Education 43 (11): 1810-1822.

Harris, Yvette R. 2017. "The Complexities in Conceptualizing Neurodiversity. Comment on; Implications of the Idea of Neurodiversity for Understanding the Origins of Developmental Disorders; by Nobuo Masataka." PhLRv 20: 115-118.

Harvey, Jonathan. 2019. "Nothing About Us Without Us! Utilising Experiences of Disability in Higher Education." The Journal of Inclusive Practice in Further and Higher Education Dec 19 (11.2): 102-117.

Hay, Iain. 2017. How to be an Academic Superhero: Establishing and Sustaining a Successful Career in the Social Sciences, Arts and Humanities. Cheltenham: Edward Elgar Publishing.

HESA. 2019. Higher Education Student Statistics: UK, 2017/18 - Student Numbers and Characteristics. Higher Education Statistics Agency. Accessed July 22, 2021. https://www. hesa.ac.uk/news/17-01-2019/sb252-higher-education-student-statistics/numbers

Higham, James, Arianne Reis, and Scott A. Cohen. 2015. "Australian Climate Concern and the 'Attitude-Behaviour Gap'." Current Issues in Tourism 19 (4): 338-354. doi:10.1080/13683500. 2014.1002456.

Hubble, Sue, and Paul Bolton. 2021. House of Commons Briefing Paper: Support for Disabled Students in Higher Education in England. Accessed July 22, 2021. https://commonslibrary. parliament.uk/research-briefings/cbp-8716/

Jackson, Scott L.J., Logan Hart, Jane Thierfeld Brown, and Fred R. Volkmar. 2018. “Brief Report: Self-Reported Academic, Social, and Mental Health Experiences of Post-Secondary Students with Autism Spectrum Disorder." Journal of Autism and Developmental Disorders 48 (3): 643-650.

James, Westley, James H. Cooney, Jacquelyn J. Chini, Eleazar Vasquez III, and Jillian Schreffler. 2021. "Using Universal Design for Learning to Support Students with Disabilities in a Scaleup Physics Course." The Physics Teacher 59 (5): 320-324.

Jansen, Dorien, Elke Emmers, Katja Petry, Laura Mattys, Ilse Noens, and Dieter Baeyens. 2018. "Functioning and Participation of Young Adults with ASD in Higher Education According to the ICF Framework." Journal of Further and Higher Education 42 (2): 259-275.

Kapp, Steven K., Kristen Gillespie-Lynch, Lauren E. Sherman, and Ted Hutman. 2013. "Deficit, Difference, or Both? Autism and Neurodiversity." Developmental Psychology 49 (1): 59.

Kenny, Lorcan, Caroline Hattersley, Bonnie Molins, Carole Buckley, Carol Povey, and Elizabeth Pellicano. 2016. "Which Terms Should Be Used to Describe Autism? Perspectives from the UK Autism Community.” Autism 20 (4): 442-462.

Kuder, S. Jay, and Amy Accardo. 2018. "What Works for College Students with Autism Spectrum Disorder." Journal of Autism and Developmental Disorders 48 (3): 722-731.

Lai, Meng-Chuan, and Simon Baron-Cohen. 2015. "Identifying the Lost Generation of Adults with Autism Spectrum Conditions." The Lancet Psychiatry 2 (11): 1013-1027.

Lee, Chung Eun, and Jennifer G. Kim. 2021. "Person-Centered Transition Planning for Youth on the Autism Spectrum: What Are We Still Missing?” Exceptionality, 1-14.

Madriaga, Manuel, and Dan Goodley. 2010. "Moving Beyond the Minimum: Socially Just Pedagogies and Asperger's Syndrome in UK Higher Education." International Journal of Inclusive Education 14 (2): 115-131. 
Márquez-Caraveo, María Elena, Rocío Rodríguez-Valentín, Verónica Pérez-Barrón, Ruth Argelia Vázquez-Salas, José Carlos Sánchez-Ferrer, Filipa De Castro, Betania Allen-Leigh, and Eduardo Lazcano-Ponce. 2021. "Children and Adolescents with Neurodevelopmental Disorders Show Cognitive Heterogeneity and Require a Person-Centered Approach.” Scientific Reports 11 (1): $1-14$.

Mayes, Susan Dickerson, Susan L. Calhoun, Michael J. Murray, Amanda Pearl, Amanda Black, and Cheryl D. Tierney. 2014. "Final DSM-5 Under-Identifies Mild Autism Spectrum Disorder: Agreement Between the DSM-5, CARS, CASD, and Clinical Diagnoses." Research in Autism Spectrum Disorders 8 (2): 68-73.

McConkey, Roy. 2020. "The Rise in the Numbers of Pupils Identified by Schools with Autism Spectrum Disorder (ASD): a Comparison of the Four Countries in the United Kingdom." Support for Learning 35 (2): 132-143. doi:10.1111/sufl.v35.2.

McMahon, Camilla M., Brianna Stoll, and Meghan Linthicum. 2020. "Perceived Versus Actual Autism Knowledge in the General Population." Research in Autism Spectrum Disorders 71: 101499.

Milton, Damian. 2014. "Autistic Expertise: A Critical Reflection on the Production of Knowledge in Autism Studies." Autism 18 (7): 794-802.

Milton, Damian, and Lyte Moon. 2012. "The Normalisation Agenda and the Psycho-Emotional Disablement of Autistic People.” Autonomy, the Critical Journal of Interdisciplinary Autism Studies 1 (1): 1-12.

Moriña Díez, Anabel, Rosario Gavira López, and Víctor M. Molina. 2015. "Students with Disabilities in Higher Education: A Biographical-Narrative Approach to the Role of Lecturers." Higher Education Research \& Development 34 (1): 147-159.

Newman, Lynn, Mary Wagner, Anne-Marie Knokey, Camille Marder, Katherine Nagle, Debra Shaver, and Xin Wei. 2011. "The Post-High School Outcomes of Young Adults with Disabilities up to 8 Years After High School: A Report from the National Longitudinal Transition Study-2 (NLTS2). NCSER 2011-3005.” National Center for Special Education Research.

NHS Digital. 2020. Autism Waiting Time Statistics. National Health Service. Accessed July 9, 2021. https://digital.nhs.uk/data-and-information/publications/statistical/autism-statistics/q1-aprilto-june-2020-21/data-quality-copy

Office for Students. 2021. "Equality, diversity and student characteristics data." Office for Students. Accessed July 22, 2021. https://www.officeforstudents.org.uk/data-and-analysis/equalitydiversity-and-student-characteristics-data/

Pellicano, Elizabeth, Adam Dinsmore, and Tony Charman. 2014. "What Should Autism Research Focus upon? Community Views and Priorities from the United Kingdom.” Autism 18 (7): 756770.

Pinder-Amaker, Stephanie. 2014. "Identifying the Unmet Needs of College Students on the Autism Spectrum." Harvard Review of Psychiatry 22 (2): 125-137.

Pino, Marco, and Luigina Mortari. 2014. "The Inclusion of Students with Dyslexia in Higher Education: A Systematic Review Using Narrative Synthesis.” Dyslexia 20 (4): 346-369. doi:10. 1002/dys.v20.4.

Pugliese, Cara E., and Susan W. White. 2014. "Brief Report: Problem Solving Therapy in College Students with Autism Spectrum Disorders: Feasibility and Preliminary Efficacy." Journal of Autism and Developmental Disorders 44 (3): 719-729.

Randall, Melinda, Emma Sciberras, Amanda Brignell, Elfriede Ihsen, Daryl Efron, Cheryl Dissanayake, and Katrina Williams. 2016. "Autism Spectrum Disorder: Presentation and Prevalence in a Nationally Representative Australian Sample." Australian \& New Zealand Journal of Psychiatry 50 (3): 243-253.

Rosqvist, H. B., Stenning A., and Chown A. 2020. "Introduction.” In Neurodiversity Studies, edited by H. B. Rosqvist, N. Chown, and A. Stenning, 1-13. Oxon: Routledge.

Rutherford, Marion, Karen McKenzie, Tess Johnson, Ciara Catchpole, Anne O’Hare, Iain McClure, Kirsty Forsyth, Deborah McCartney, and Aja Murray. 2016. "Gender Ratio in a Clinical Population Sample, Age of Diagnosis and Duration of Assessment in Children and Adults with Autism Spectrum Disorder." Autism 20 (5): 628-634. 
Sarrett, Jennifer C. 2018. "Autism and Accommodations in Higher Education: Insights from the Autism Community." Journal of Autism and Developmental Disorders 48 (3): 679-693.

Shmulsky, Solvegi, Ken Gobbo, and Steven Vitt. 2021. "Culturally Relevant Pedagogy for Neurodiversity." Community College Journal of Research and Practice, 1-5.

Silva-Fletcher, Ayona, and Stephen A. May. 2018. "Discipline-Specific Compared to Generic Training of Teachers in Higher Education." Journal of Veterinary Medical Education 45 (1): $1-10$.

Sims, T., D. Milton, N. Martin, and J. Dawkins. 2016. "Developing a User Informed Training Package for Mentoring People on the Autism Spectrum." Journal of Inclusive Practice in Further and Higher Education 7 (1): 49-52.

Stagg, Steven D., and Hannah Belcher. 2019. "Living with Autism Without Knowing: Receiving a Diagnosis in Later Life." Health Psychology and Behavioral Medicine 7 (1): 348-361.

Starr-Glass, David. 2020. "Significant Learning Experiences and Implied Students." On the Horizon 28 (1): 55-62.

Sun, Xiang, Carrie Allison, Liping Wei, Fiona E. Matthews, Bonnie Auyeung, Yu Yu Wu, Sian Griffiths, Jie Zhang, Simon Baron-Cohen, and Carol Brayne. 2019. "Autism Prevalence in China is Comparable to Western Prevalence." Molecular Autism 10 (1): 7.

Ulriksen, Lars. 2009. “The Implied Student." Studies in Higher Education 34 (5): 517-532.

VanBergeijk, Ernst, Ami Klin, and Fred Volkmar. 2008. "Supporting More Able Students on the Autism Spectrum: College and Beyond.” Journal of Autism and Developmental Disorders 38 (7): 1359.

Van Hees, Valérie, Tinneke Moyson, and Herbert Roeyers. 2015. "Higher Education Experiences of Students with Autism Spectrum Disorder: Challenges, Benefits and Support Needs." Journal of Autism and Developmental Disorders 45 (6): 1673-1688.

Vigors, Belinda. 2018. "Reducing the Consumer Attitude-Behaviour Gap in Animal Welfare: The Potential Role of 'Nudges'.” Animals 8 (12): 232.

Vincent, Jonathan, Megan Potts, Daniel Fletcher, Simon Hodges, Jenny Howells, Alex Mitchell, Brett Mallon, and Thomas Ledger. 2017. "I Think Autism is Like Running on Windows While Everyone Else is a Mac': Using a Participatory Action Research Approach with Students on the Autistic Spectrum to Rearticulate Autism and the Lived Experience of University." Educational Action Research 25 (2): 300-315.

Waisman, T. C., and M. Simmons. 2018. "Autism Spectrum Disorder and the Implications for Higher Education." The Journal of Educational Thought (JET)/Revue de la Pensée Éducative 51 (3): 317-338.

White, Devon, Ashleigh Hillier, Alice Frye, and Emily Makrez. 2019. "College Students' Knowledge and Attitudes Towards Students on the Autism Spectrum." Journal of Autism and Developmental Disorders 49 (7): 2699-2705.

Zeedyk, Sasha M., Yasamine Bolourian, and Jan Blacher. 2019. "University Life with ASD: Faculty Knowledge and Student Needs.” Autism 23 (3): 726-736. 